\title{
¿ES POSIBLE CONSTRUIR UNA ESCUELA SIN EXCLUSIONES?
}

IS IT POSSIBLE TO BUILD A SCHOOL WITHOUT EXCLUSION?

Miguel López MELERO ${ }^{1}$

RESUMEN : este artículo plantea, fundamentalmente, que no se debe confundir integración educativa con escuela inclusiva y que, probablemente, esta confusión ha originado interpretaciones dispares que está originando una serie de barreras para la presencia, aprendizaje y participación de las personas y culturas diferentes en el aula. Se analizan solo las barreras didácticas y se propone como se pueden salvar las mismas para construir una escuela sin exclusiones.

PALA BRA S CLA VES: educación especial; integración; inclusión; cultura de la diversidad; personas diferentes; barreras didácticas.

A BSTRACT: the main idea in this article is that we must not confuse the concept of "educational integration" with "inclusive schooling". Probably, such confusion has generated different interpretations of the above concepts resulting in barriers in learning and participation in the classroom for those who are different or who come from diverse cultural backgrounds. The article analyses mainly barriers in didactics and suggests how to overcome them in order to construct a school without exclusion.

KEYWORDS: special education; integration; inclusion; cultural diversity; difference; barriers in didactics.

\section{INTRODUCCIÓN}

Mi primera respuesta a esteinterrogantees queno sól o es posible, sino que es necesario, y como es necesario hemos dellevarlo a cabo. Para ello hemos de buscar, y saber encontrar, cuáles son las barreras que impiden la presencia, el aprendizaje y la participación de las personas y culturas diferentes en la escuela pública. Esta es la cuestión fundamental que tiene planteada en la actualidad la escuela pública. Yo, con cierta humildad, voy a describir mis puntos de vista al respecto. Para ello, semeocurre partir del siguiente principio dela Conferencia de Salamanca:

El principio rector de este Marco de A cción es que las escuelas deben acoger a todos los niños independientemente de sus condiciones físicas, intel ectuales, emocionales, lingüísticas u otras [...] Las escuelas tienen que encontrar la manera de educar con éxito a todos los niños, incluidos aquellos con discapacidades graves [...]. (UNESCO, 1994, p. 59-60)

\footnotetext{
${ }^{1}$ Universidade de Málaga, Espanha. - parages2003@terra.es 
Las iniciativas internacionales delas Naciones Unidas y dela UNESCO han apostado, decididamente, hacia la necesidad de que todos los niños y todas las niñas tienen derecho de ser educados todos juntos independientemente de la etnia, del género, del handicap, de la religión o de la procedencia. De lo que se trata no es sólo de ofrecer el derecho a la educación a todos los niños y niñas, sino en ofrecerle una educación de calidad y ésta solo se consigue cuando todas las niñas y todos los niños se educan juntos. En esto, precisamente, consiste la educación inclusiva. A veces no se tiene claro de qué hablamos cuando hablamos de educación inclusiva.

Hablar de educación inclusiva no es hablar de integración. La educación inclusiva es un proceso para aprender a vivir con las diferencias de las personas. Es un proceso de humanización y, por tanto, supone respeto, participación y convivencia; sin embargo, la integración hacealusión a quelas personas diferentes y los colectivos minoritarios se han de adaptar a una cultura hegemónica. Por eso hablar de educación inclusiva, desdela cultura escolar, requiere estar dispuestos a cambiar nuestras prácticas pedagógicas para que cada vez sean prácticas menos segregadoras y más humanizantes. Cambiar las prácticas pedagógicas significa que la mentalidad del profesorado ha de cambiar respecto a las competencias cognitivas y cultural es delas personas diferentes, que han de cambiar los sistemas de enseñanza y aprendizaje, el currículum escolar, la organización escolar y los sistemas de eval uación. Esto es así, y si no es así, tiene que serlo. Si no estamos de acuerdo con este principio no vale la pena seguir escribiendo (o leyendo este artículo), porque todo lo que en él vas a encontrar está relacionado con esta visión dela escuela pública como lugar dondelas niñasy los niños aprenden a ser personas democráticas, libres, cultas y respetuosas con la diversidad.

Con esta preocupación de fondo escribo este ensayo que titulo: ¿Es posible construir una escuela sin exclusiones? Para ello voy a exponer qué barreras obstaculizan la presencia, el aprendizajey la participación delas personas diferentes y de las culturas minoritarias en la escuela pública que están impidiendo la construcción de una escuela para todas y para todos (UNESCO, 1990). Señalaré sólo las barreras didácticas, pero no podemos olvidar que también hay barreras culturales y políticas que condicionan las barreras didácticas, pero por queno son motivo de este artículo. Al final señalo cuál es mi compromiso como intelectual comprometido y como persona entusi asta que aspira, aunque sea simbólicamente, por la construcción de una sociedad sin exclusiones. Es decir, por una sociedad más culta, más libre, más solidaria, más justa, más democrática... más humana, que nos ayude a proyectar un mundo mejor. ¿Quién no desea un mundo mejor?

Estamos inmersos en un mundo de una opulencia sin precedentes, difícil de imaginar hace cincuenta años cuando yo era niño. Donde no sólo se han registrado notables cambios en el terreno económico, sino en lo social y en lo político. Si en la época clásica el centro del mundo era el hombre y en la Edad Media lo era Dios, en la actualidad lo es la economía. Detal modo queen la segunda mitad del siglo XX se ha ido consolidado, al amparo de lo económico, un sistema 
de 'gobierno democrático' formalmente hablando, como modelo de organización política, que ha hecho olvidar, precisamente, los valores de la propia democracia como son la libertad y la igualdad. Sabemos que dela libertad emergela tolerancia y el respeto, y de la igualdad surge la solidaridad y la generosidad, y de ambas, la convivencia democrática y el progreso humano. Todo ello hacequeen la actualidad los conceptos de Derechos Humanos y de libertad política formen parte, en gran medida, de la retórica imperante en una sociedad que, curiosamente, no creen en ellos. Precisamentelos Derechos Humanos se configuran a raíz de aquellos valores. De la libertad nacen los derechos civiles y políticos y de la igualdad, los derechos económicos, sociales y culturales.

Todos los seres humanos pertenecen a la misma especie y tienen el mismo origen. Nacen iguales en dignidad y en derechos y todos forman parte integrante de la humanidad. Todos los individuos y grupos tienen derecho a ser diferentes, a considerarse y ser considerados como tales. Sin embargo, la diversidad de las formas de vida y el derecho a la diferencia no pueden en ningún caso servir de pretexto a los prejuicios raciales; no pueden legitimar ni en derecho ni de hecho ninguna práctica discriminatoria (unEsco, 1981, p. 2)

Vivimos, por término medio, mucho más y mejor que antes, gracias a los avances médicos y a las mejoras en las condiciones de vida. Es cierto que hoy, debido a las nuevas tecnologías, mantenemos más lazos que nunca entre las distintas partes del mundo, no sólo en el campo del comercio y de las comunicaciones, sino también en el delas ideas y de los ideales interactivos. Y, no obstante, también vivimos en un mundo de notables privaciones, miserias y opresión. Hay muchos problemas antiguos sin resolver, y entreellos sobresal en la persistencia dela pobreza y muchas necesidades bási cas insatisfechas, el problema del hambre en el mundo, la violación de libertades políticas elementales, así como de libertades básicas, la falta general de atención a los intereses comunes y la participación limitada delas mujeres, la segregación de las culturas minoritarias y delas personas diferentes, el empeoramiento de las amenazas que seciernen sobre nuestro medio ambiente y sobre el mantenimiento de nuestra vida económica y social. Muchas de estas privaciones se observan, de una u otra forma, tanto en los países ricos como en los pobres pero, obviamente, más en los países pobres.

Lo que deseo decir con estas primeras palabras es que siento que el mundo está enfermo, pero no es una enfermedad cual quiera la que padecemos, estamos aniquilando el mundo tanto en lo ecológico como en las relaciones humanas. La enfermedad del mundo es una ausencia casi total delo más hermoso y genuino de los seres humanos: el amor. Lo que yo entiendo por amor no tiene nada que ver con ese concepto poético, religioso o filosófico con el que a veces se envuelve a aquél; mi concepción de amor está relacionada sencillamente con el respeto a las personas como legítimas personas en su diferencia, independientemente del handicap, del género, de la etnia, religión o procedencia, etcétera. Sólo en el reconocimiento de las personas como personas, sin ningún tipo de añadido, radica el sentido de lo humano. Precisamente por eso el sentido de lo 
humano se construye desde el significado que le demos a la diferencia, si como valor o como defecto y lacra social. Si la diferencia la consideramos como una lacra, estaremos en el discurso de la integración, si la consideramos como un valor estaremos en el discurso de la educación inclusiva. No es sólo acoger al otro, sino valorarlo. Estereconocimiento dela normalidad dela diversidad es lo queconfigura la dignidad humana. La diferencia es lo normal. Comprender esto es ya un valor. Y esto es lo natural. Lo antinatural es lo contrario: la homogenización.

Desde esta perspectiva meplanteo el interrogante ¿es posibleconstruir una escuela sin exclusiones?, y mi pensamiento es que la escuela pública en estos momentos necesita un nuevo proyecto educativo que haga realidad la inclusión en sus aulas. Un nuevo model o educativo que ha de construirse sobre la base dela comprensión de que todas las personas que acuden a la escuela son competentes para aprender. A ceptar esteprincipio es iniciar la construcción de un nuevo discurso educativo al considerar la diferencia en el ser humano como un valor y no como defecto y, a partir de ahí renacerá una cultura escolar que al respetar las peculiaridades eidiosincrasia de cada niña y decada niño evitará las desigual dades.

\section{¿ES POSIBLE CONSTRUIR UNA ESCUELA SIN EXCLUSIONES?}

Durante mucho tiempo se ha pensado que la educación inclusiva consistía en "integrar" niños con al gún tipo de discapacidad en la escuela, pero sin que ello significara ningún tipo de cambio en la misma, y lo que es peor aún, sin que cambiasenada el pensamiento del profesorado ni su práctica educativa. Desde mi punto de vista la educación inclusiva es la lucha contra la segregación, porque lo que está en juego no es que las personas diferentes aprendan más o menos estando con el resto de los niños en el aula, sino que la escuela pública tiene que ofrecer otro modelo educativo donde aprendan todos juntos a convivir.

Estereto no es sólo del profesorado, aunque es piedra angular, sino de toda la comunidad escolar. Cuando hablo de comunidad no sólo incluyo a las familias y al entorno social cercano a las mismas, sino también a la universidad. Y lo hago porquees absolutamentenecesario queel profesorado universitario también tome conciencia de que es en las aulas universitarias donde hay que iniciar este cambio de mentalidad con los estudiantes que desean ser docentes. Es en la universidad donde deben ir adquiriendo el conocimiento, la formación y las actitudes sobre lo que conlleva y significa la educación inclusiva. La pregunta que subyace a esto que vengo afirmando es si nuestra práctica educativa contribuye o no a construir una escuela sin exclusiones

En este sentido me atrevo a señalar que sólo se logrará esa escuel a sin exclusiones si somos capaces de derribar las barreras que están impidiendo la presencia, el aprendizaje y la participación delas personas y colectivos diferentes en nuestras escuelas. Desde mi punto de vista estas barreras son las siguientes: culturales (conceptuales y actitudinales), políticas (normativas contradictorias) y 
didácticas (enseñanza-aprendizaje). Por las condiciones de este artículo sólo me voy a dedicar a exponer las barreras didácticas (procesos deenseñanza-aprendizaje), aunque sería muy interesante profundizar en las restantes barreras.

\section{Barreras Didácticas (Enseñanza-a prendizaje)}

Pueden ser muchas las barreras didácticas que impiden la construcción de una escuela donde nadie se sienta excluido. Yo voy a anotar aquellas que, a mi juicio, me parecen más relevantes y, asimismo, señalaréal gunos mecanismos para ir superándolas.

Primera: La permanente actitud de clasificar y establecer normas discriminatoria. (Etiquetaje del alumnado)

La primera barrera que impide la presencia, el aprendizaje y la participación dealumnado en las aulas es la cultura generalizada, en la comunidad educativa, de que hay dos tipos diferentes de alumnados, los alumnos 'comunes' y los alumnos 'especiales'. Ello está basado en la creencia de que hay alumnos 'normales' y alumnos 'discapacitados' y, lógicamente, se tiene el convencimiento de que éstos últimos requieren técnicas diferentes de enseñanza. Como consecuencia de esta dicotomización, en niños comunes y especiales, se emplea gran cantidad de tiempo y esfuerzo buscando una clasificación diagnóstica para determinar quién es 'normal' y quién es 'especial', pese al hecho de que hay gran cantidad de investigaciones internacionales que indican que dichos diagnósticos y clasificaciones se hacen de manera poco fiable. Hay que romper la cultura de la desconfianza en las competencias cognitivas y cultural es delas personas diferentes y vivir en la cultura de la confianza. Esta es la cultura que inunda el Proyecto Roma (LÓPEZ MELERO, 2003)²

En este sentido los conceptos de inteligencia y de diagnóstico han ejercido un papel de discriminación y segregación. Últimamente también el de 'adaptaciones curriculares'. Por ello para derribar esta barrera hemos de dejar claro quéentendemos por intel igencia y quéentendemos por diagnóstico. Mejor aún, la cuestión que deseo plantearles es si es correcto plantearse ¿qué es la inteligencia?. Tradicional menteasí se ha hecho y se ha respondido que cada ser humano vienea este mundo predeterminado biológicamente (infradotado, dotado, superdotado). En este sentido seha considerado la inteligencia como un atributo de esta o aquella

\footnotetext{
2 “El Proyecto Roma», como proyecto de investigación pretende aportar ideas y reflexiones sobrela construcción de una nueva teoría de la inteligencia, a través del desarrollo de procesos cognitivos, afectivos, lingüísticos y de autonomía en las personas con síndrome de Down. Como proyecto de educación, su finalidad básica y fundamental secentra en mejorar los contextos familiares, escolares y sociales, desdela convivencia democrática, el respeto mutuo y la autonomía personal, social y moral.
} 
persona o como una propiedad individual independiente del contexto donde uno nace y vive. Ante esta actitud no hay posibilidad de educación alguna con un pensamiento determinista como éste. Sin embargo, yo pienso que la pregunta ¿qué es la inteligencia? Está mal formulada y lo que tendríamos que preguntarnos es ¿cómo se produce el comportamiento inteligente en las personas? En este caso la inteligencia ya no es considerada como un atributo sino como al go quese adquiere, que se desarrolla y que se construye gracias a la educación y a la cultura, siempre y cuando los contextos ofrezcan oportunidades para ello. Lo importante, por tanto, es saber que la inteligencia no viene determinada genéticamente, si no quelos seres humanos nos hacemos inteligente. Venimos al mundo como seres inacabados y nos completamos gracias a la cultura y a la educación. La inteligencia como la deficiencia se construye.

¿Dequéhablamos cuando hablamos de inteligencia? ¿Dela inteligencia cognitiva? ¿De la inteligencia lingüística? ¿De la inteligencia afectiva? ¿De la inteligencia motriz?... Como muy bien describe Gardner (1995) en su teoría de las Inteligencias Múltiples y asume una perspectiva amplia y pragmática de la inteligencia, más allá de la perspectiva restringida de la medición de $\mathrm{Cl}$ mediante tests psicométricos. Entiendeesteautor quela inteligencia no es única, ni monolítica. Define siete inteligencias o áreas de talento referidas al lingüístico, lógicomatemático, artístico, corporal-cinestésico, musical, social (inter e intrapersonal). Más tarde, en 1998, postula el octavo talento, al que denomina científico.

¿Qué pasa entonces con la genética en las personas diferentes, se preguntarán al gunos? Con la genética no pasa nada tan sólo es una posibilidad, no un epitafio. Lo que constituye al ser humano como tal es la dimensión social. Lo genético no determina lo humano, sólo fundamenta lo humanizable o lo posiblemente humanizable. La dotación génica sólo delimita cursos potenciales de acción posibles que, a modo de itinerarios personales, van a ir cambiando en función dela educación. Por ello, no meparecedeterminantela condición genética, aunque no podemos olvidarla, ni tampoco las peculiaridades quesepuedan derivar de la misma. Sin embargo, me parece muy relevante subrayar las competencias cognitivas y culturales delas personas diferentes para romper con el determinismo biológico. Para ello hay que despertar, en primer lugar, la confianza en las madres y los padres que suelen ser informados por los expertos (a veces de la medicina y de la psicología) de las escasas competencias de sus hijos, y confianza del profesorado para quese afanen en buscar otros model os educativos que propicien el cambio, y, sobre todo, habría que poner mucho empeño en saber cómo viven estas personas dichas competencias y cómo las desarrollan a lo largo de su propio proceso de aprendizajecuando se 'educa' sin esperanza en el cambio. Es decir, que las personas diferentes son mucho más que su carga genética, son, fundamental mente, un organismo que funciona como un todo y la genética es sólo una posibilidad. Todo nuestro ser funciona como un todo. Cuando seconsideran a las personas diferentes como un todo, los procesos lógicos de pensamiento compensan y equilibran sus peculiaridades (VYGOTSKY, 1978). 
En consecuencia las investigaciones relacionadas con las personas diferentes han de cambiar y tienen que focal izarse hacia otro tipo de estudios. ¿Qué estudios? Aquellos que nos permitan reconstruir una nueva visión de las posibilidades y competencias de las personas diferentes que rompa la vieja idea creada de que la desigual dad entre las personas es al go natural einevitabley, dado que las personas cognitivamente diferentes han sido programadas genéticamente, de nada vale despilfarrar medios y recursos, porque nada va a cambiar. Esta idea fatalista del fundamentalismo genético (determinismo biológico y sociobiológico), hoy en día, no resisteel menor análisis crítico precisamenteporquelas desigualdades no están en los genes, sino en el contexto social (LEWONTIN, 1990).

Este cambio de punto de vista se acompaña con una manera diferente de definir la discapacidad en sí misma, dejando atrás la influencia médica y psicológica quefocal iza los handicaps sobrelas personas, y seponeel énfasis en las situaciones problemáticas de los contextos. ¿Hasta qué punto determinadas 'discapacidades' dependen en gran medida dela naturaleza delas situaciones que los individuos tienen que afrontar en la vida? Las razones por las cuales las niñas y los niños pueden experimentar dificultades en la escuela son complejas y probablemente no son inherentes a ellos, tales como: curriculum, métodos de enseñanza y aprendizaje, organización escolar y sistemas deevaluación inflexibles. Es decir, pedagogías incorrectas. En este sentido podemos llegar a afirmar que el número de niñas y niños con 'dificultades' para aprender está relacionado con la calidad educativa que le ofrezca la escuela.

Relacionado con el concepto de inteligencia se encuentra también el concepto de diagnóstico. Tradicional mente se ha consi derado el diagnóstico como una 'vara de medir' etiquetando a las personas diferentes como enfermosretrasados-subnormales-deficientes, configurando una subcategoría humana, la minusvalía (Paradigma Deficitario). Esta concepción de diagnóstico no ofrece ninguna posibilidad de cambio en las personas, es un diagnóstico, fragmentado, estático, determinista, clasificador. Yo diría que no es un diagnóstico, es un castigo: "así eres y debes resignarte, porque así seguirás siendo el resto de tus días". Sin embargo, mi pensamiento es queel diagnóstico no es al go perverso. Al contrario el diagnóstico es como el umbral del conocimiento, es como una puerta abierta a la indagación y al descubrimiento: a la búsqueda.

El diagnóstico nos dice cómo se encuentra esta o aquella persona en este momento, pero que en modo al guno sabremos cómo estará mañana y menos si su desarrollo depende dela educación. El desarrollo humano no consistesól o en señal ar lo que uno es ahora, sino lo que puede ser con la ayuda educativa de los demás y con la cultura. El desarrollo depende del devenir. Es algo que está por hacer. Es decir que el desarrollo depende de la oferta educativa, y si ésta es de calidad, el desarrollo será de calidad. De ahí el carácter educativo y ético del diagnóstico. El diagnóstico tiene su ética (descripción del fenómeno) y su moral (prescribir cómo salir de esa situación). 
Si logramos romper con estos dos conceptos clásicos iniciaremos un proceso deruptura del Paradigma Deficitario a favor del Paradigma Competencial. Esto no es un paso banal eingenuo, al contrario muy significativo, porquees pasar del modelo compensatorio al educativo.

\section{CAMBIO DE PARADIGMA}

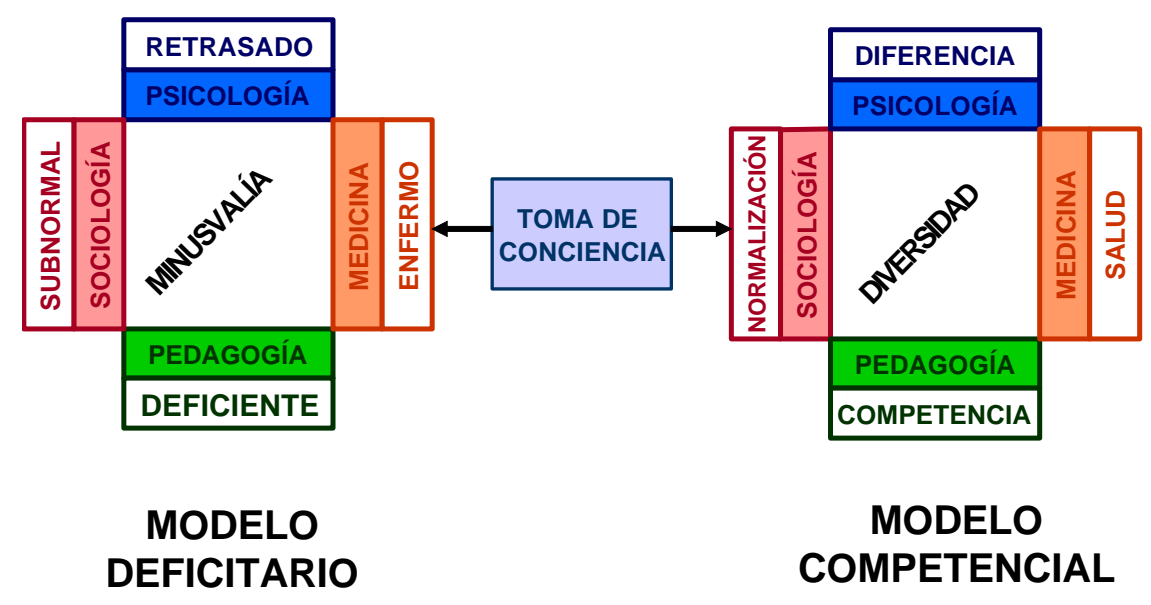

Por todo ello, desde un punto de vista pedagógico, no podemos considerar sólo un cambio meramente estructural, sino que ello exige un «cambio de paradigma», en el sentido que lo utilizaba Kuhn (1977), ya que se requiere cambiar el Paradigma Deficitario, de influencia médica y psicológica queconsidera a las personas diferentes como enfermos-retrasados-subnormales-deficientes, configurando todo ello una categoría humana minusval orizada (Minusvalía), donde las únicas culpables son las personas con handicaps por sus dificultades para aprender, por el Paradigma Competencial Educativo que reconoce a aquellas como competentes para aprender.

Cuando esto se entiende y se comprende, es decir cuando se practica, la vida en las aulas de las escuelas es más fácil. Es decir, cuando las niñas y los niños comprenden que todos sus compañeros pueden aprender y que unos aprenden de una manera y otros deotra, pero todos, ayudándose, lo van a conseguir es cuando el aula se convierteen una comunidad de convivencia y aprendizaje. Es entonces cuando el resto de la cultura escolar se convierte en un camino fácil para la convivencia democrática. De eso se trata de quelas aulas sean comunidades de convivencia y aprendizaje. 
Si esta primera barrera somos capaces de salvarla el resto de las que a continuación expongo serán más fáciles desuperar, pero si no seconsiguesuperarla, por mucho que hagamos sobre las restantes barreras siempre preval ecerá la concepción y la consideración de que las personas diferentes son 'deficientes' y estableceremos nuestras relaciones en función de esta consideración. Lamentablemente esta actitud 'imprime carácter'.

Segunda: La competitividad en las aulas frenteal trabajo cooperativo y solidario. Cuando el aula $\mathrm{N}$ o es considerada como una comunidad de convivencia y de aprendizaje

Deacuerdo con lo anterior, podemos afirmar quelas personas diferentes no necesitan una educación reparadora denada, porque no son un desperfecto de la naturaleza, sino que necesitan una educación de calidad. Y esta educación de calidad se debe llevar a cabo en compañía de los demás niños y niñas, porque lo que está en juego no es el aprendizaje de las personas diferentes, sino al go mucho más importante: el propio aprendizaje como fenómeno biológico y social y éste, sabemos que es una actividad compartida con otros, y el aprendizaje compartido produce una inteligencia compartida. La enseñanza yo la considero como esa actividad solidaria que 'hace aprender a otros, aprendiendo uno mismo' y estees el compromiso dela escuela pública: el aprender unos deotros a construir modelos deconvivencia y aprendizaje. Si no seabre este espacio de convivencia difícilmente aparecerá el aprendizaje y la participación.

Entiendo el aula como comunidad deconvivencia y aprendizajecuando se produce un intercambio de significados y comportamientos, de recuerdos y experiencias, de sentimientos y emociones, configurándose un espacio cultural y una organización con pretensiones comunes y con el deseo de entenderse y respetarse. Y eso sólo es posible si las niñas y los niños tienen la oportunidad de intercambiar sus experiencias (diálogo) personales, deintercambiar puntos devista diferentes, realizando actividades de manera cooperativa y solidaria y estableciendo unas normas de convivencia democrática entre todas y todos (buscando el entendimiento) y donde, previamente, tiene que haberse producido una situación de interés y significación para hacer aquello que desean hacer (motivación intrínseca).

Cuando el profesorado toma conciencia de la importancia de estas interacciones y logra que esta conciencia sea accesible a otros como ayuda para lograr conocimiento y estrategias para resolver situaciones problemáticas de la vida cotidiana, se puede asegurar que en esa clase se está desarrollando una convivencia democrática más allá de la cultura específica que se esté proporcionando. Así quela educación de cada niña y decada niño está mediatizada por la cultura del profesorado y de sus propios compañeros. Sólo en las escuelas democráticas se insiste en la necesidad de construir comunidades de convivencia y aprendizaje, donde la cooperación es mucho más que la mera colaboración. 
Tercera: D el currículum basado en disciplinas y en el libro de texto a un currículum basado en situaciones problemáticas. R uptura con las adaptaciones curriculares.

Dar sentido a la diversidad del alumnado de nuestras escuelas tiene que ser el epicentro del desarrollo del curriculum escolar a través de la calidad de las relaciones. En este punto hemos de orientar todos los esfuerzos para romper con la cultura hegemónica en la escuela tradicional deseosa de desarrollar un curriculum planificado e igual para todos. El curriculum es - y debe ser - una herramienta para la inclusión y no puede convertirse en la práctica en un instrumento de exclusión, dando a unos la cultura general establecida y a otros la subcultura o produciendo subcultura, porque si la cultura produce desarrollo, la subcultura produce subdesarrollo. Las adaptaciones curriculares, en la mayoría de los casos, es subcultura, por tanto, produce subdesarrollo.

La construcción de un curriculum inclusivo, diversificado y transformador no es sólo cuestión de intenciones, sino también de prácticas construidas socialmente y, sobre todo, de actitudes. En este sentido desde el Proyecto Roma hablamos de proyectos de investigación cuando hablamos decurrículo donde no se parte de las disciplinas ni de los libros de textos, sino de situaciones problemáticas, dondelas niñas y los niños aprenden los mecanismos para descubrir la cultura a través de la indagación y la cooperación. La idea de proyecto, en el Proyecto Roma, no es la idea detema en sentido tradicional, y que secuencialmente se aprende uno detrás del otro. Tampoco es una taxonomía de objetivos que ordenadamente han de conseguirse. Lo que pretendemos con los proyectos de investigación es lograr una metodología que favorezca el aprendizaje autónomo, mediantela toma de decisiones reales y el desarrollo de estrategias para 'aprender a aprender' (metacognición), tales como: planteamiento de problemas o situaciones problemáticas y explicación de las mismas, discusión y debate, búsqueda de información más allá de la clase, trabajo cooperativo y solidario en grupos heterogéneos, elaboración de mapas conceptuales, construcción de esquemas mentales, etc. Donde el error es importante como medio de aprendizaje. Los proyectos son un modo de 'aprender a aprender en colaboración'. Es decir, un modo de 'enseñar a pensar y de enseñar a hacer', dondeel debate dialógico que acompaña a todo el proceso inclina al profesorado y al alumnado a llegar a un consenso antes de tomar cualquier decisión (HABERMAS, 1999). Para nosotros, en el Proyecto Roma, es una actitud de búsqueda e indagación permanente en el aula, un modo de investigar. Desde este punto de vista el aula no puede ser sólo un lugar para adquirir conocimientos sino para aprender a descubrirlos de manera compartida con los demás y en este compartir también se han de adquirir otros valores.

Efectivamentela escuela pública seencuentra hoy en día anteel dilema de socializar a su alumnado ante unos valores sociales perversos tales como el individualismo, la insolidaridad, el consumismo, la competitividad y el narcisismo propios de la sociedad neoliberal en la que nos encontramos o educarlo contrarrestando dichos valores a través de vivir en sus aulas la democracia, el respeto, la solidaridad, Ia convivencia, la ética, la justicia, la dignidad, el amor, etc. 
A hora bien ¿los val ores se enseñan o los val ores se viven? Y la respuesta es quelos valores no se enseñan sino que se viven y en este vivir los valores radica el valor moral de los mismos.

La escuela sin exclusiones no tiene que ver sólo con la Didáctica y lo didáctico, ni con la investigación e innovación educativa, sino con el mundo delos valores, por tanto, tiene que ver no sólo con el vivir juntos, sino con el aprender a convivir. A saber convivir no se aprende a través de una serie de objetivos ni a través de una serie de normas aprendidas, a convivir se aprende conviviendo. La convivencia así entendida deja de ser un objetivo en la escuela de la diversidad para convertirse en un principio, dado que supone el reconocimiento de la legitimidad del otro como verdadero otro en la convivencia.

Cuarta: De la organización espacio-temporal clásica a una organización de acuerdo a la actividad a realizar. U na nueva organización para una nueva escuela.

El trabajo por proyectos de investigación requiere una transformación del aula tanto en los agrupamientos como en la concepción del tiempo y del espacio. La enseñanza interactiva y el trabajo por grupos heterogéneos y de manera cooperativa han deser la nueva estructura organizativa del aula. Ésta seorganizará de tal manera que el alumnado se ayude unos a otros $y$, aunque el alumnado que 'no ofrezca dificultades' (sí es que éste existe) sea un soporte importante para aquellos quesí las tengan, el profesorado será siempreel principal apoyo en clase para todos.

Para conseguir esto desdeel Proyecto Roma lo quehacemos justamente es convertir el contexto aula en una situación desimulación del cerebro - "el contexto es el cerebro" (LURIA , 1974), estableciendo para ello cuatro zonas queseidentifican con las cuatro áreas de desarrollo humano: esas zonas son: a) Zona de Pensar (para el desarrollo de procesos cognitivos y metacognitivos); b) Zona de Comunicar (lenguajes y sistemas de comunicación); c) Zona del A mor (afectividad y mundo de los valores) y d) Zona del Movimiento (autonomía física, personal, social y moral) (LÓPEZ MELERO, 2004).

Con este procedimiento de trabajo en el aula lo que deseamos es que las niñas y los niños sean conscientes de su propio proceso de pensar a través de procesos de reflexión y autocorrección, es decir, que adquieran un proceso lógico de pensamiento. Pero también pretendemos que construyan sus criterios y puntos de vista personales para modificar sus pensamientos y sus acciones y, en consecuencia, para fortalecer su competencia para tener correctos juicios y para aprender a tratarse unos a otros de manera razonable y respetuosa. En una comunidad de indagación y de aprendizaje de este tipo (investigación), tanto el propio proceso de pensar como aquellos que participan en él se transforman y se enriquecen, no sólo cognitiva y culturalmente, sino afectiva y comportamentalmente. 
La construcción de estos ambientes escolares con estructuras organizativas y metodológicas democráticas posibilitará al alumnado y al profesorado una nueva axiología al introducirse en los centros educativos nuevas preocupaciones tales como el pluralismo, la libertad, la justicia, el respeto mutuo, la tolerancia, la solidaridad, la democracia, etc. El aprendizaj.e cooperativo en el aula posibilitará una ciudadanía más dialogante, más solidaria y más democrática

Quinta: La necesaria reprofesionalización del profesorado para la comprensión de la diversidad. D el profesor como técnico-racional al profesor como investigador

Se necesita un nuevo profesional para darle sentido a este modo de concebir la cultura de la diversidad donde el profesorado ha de dejar de ser un profesional como mero aplicador de técnicas y procedimientos (racionalista y técnico) y se ha de convertir en curioso intelectual comprometido (investigador) que sepa abrir espacios para que el aula se transforme en un lugar de aprendizaje compartido y autónomo, desarrollando su autonomía y su libertad como docente comprometido para el cambio y la transformación social, es decir, como un profesional emancipado, evitando así ser un instrumento instrumentalizado del sistema. Todo ello exige una serie de competencias profesional es que le permita, por un lado saber conjugar los conocimientos y los procesos con las actitudes para lograr una intervención autónoma y eficienteen el aulay, por otro, compartir con otros colegas la reflexión de su práctica.

La dialéctica acción-reflexión condiciona tanto el pensamiento como la acción, de modo queambos momentos seiluminen, se valoren y se enriquezcan mutuamente. En estesentido, y sólo en estesentido, el desarrollo profesional puede hacer que el profesorado se haga más conocedor desí mismo y estémás seguro de su práctica a través de su propia reflexión (autorreflexión) y valoración. Ni la acción excesiva y mecanizada ni la más hermosa teoría concientizadora llevan a la verdadera acción transformadora y consciente (praxis). Como nos recuerda Freire (1990, p. 211) «La conciencia, no se transforma a través de cursos y discursos, o de sermones elocuentes, sino por la acción de los seres humanos sobre el mundo [...] Supone conjunción entre teoría y práctica en la que ambas se van constituyendo, haciéndose en un movimiento permanente de la práctica a la teoría y deésta a una nueva práctica».

Sexta: La escuela pública y el aprender participando entre familias y profesorado. D e las escuel as antidemocráticas a las escuel as democráticas

La educación en valores, necesaria en la escuela pública, cuya finalidad es formar una ciudadanía responsable, no puede ser una labor exclusiva del profesorado, sino que debe ser una tarea compartida entre las familias, el profesorado y los demás agentes educativos. Sólo se rompe con el modelo de educación anti democrática viviendo en democracia en la escuela y los dos valores 
que definen una situación democrática son la libertad, que genera la virtud de la tolerancia y el respeto, y la igualdad que produce la solidaridad y la generosidad entre todos. Hablar de convivencia democrática en el aula es hablar de convivir democráticamentedesdela participación y el respeto mutuo en los diferentes roles que han de desempeñar las familias, el profesorado y el alumnado.

Cuando hablo deescuel a pública como una escuela sin exclusiones, no hablo de educar 'para' la democracia, ni 'para' la libertad ni 'para' la justicia, sino de educar 'en' la democracia, 'en' la libertad y 'en' la justicia. No son objetivos a conseguir, sino principios de acción. Procurar que a lo largo de todo el proceso educativo la niña y el niño actúen como persona libre y responsable, es educar en la democracia, en la justicia y en la li bertad. Precisamente, formar una ciudadanía para que aprenda a participar en la vida pública de la sociedad en la que vive, ha de ser uno de los principales objetivos de la escuela pública.

La democracia sólo se puede dar en la diversidad. La democracia necesita de actitudes y comportamientos democráticos para ser democracia, lo que requiere que se respete y se contemple la diferencia, sin marcar desigualdades. Cuando no se entiende el valor de la igualdad como respeto a la diferencia se produce la tiranía de la igualdad, que es un trato idéntico a cada persona sin contemplar sus peculiaridades cualitativas.

Por todo ello sehace necesaria una legislación contra la discriminación. A unque dispongamos de una legislación sobre 'la cultura de la integración', ésta no seha interpretado bien o sencillamente no secumple. La cultura dela diversidad es la cultura de la ética. La ética surge cuando me preocupan las consecuencias de lo que hago en relación con otro u otra, y la moral es cumplir con las normas. Pero no siempre las normas son humanamente correctas, por eso la desobediencia, en algunos casos, es un acto de responsabilidad. Precisamente porque hay que aprender a decir NO antes de cometer una inmoralidad.

La educación para la convivencia democrática y participativa nos abre la esperanza para la construcción de un proyecto de sociedad y de humanización nueva, donde el pluralismo, la cooperación, la tolerancia y la libertad serán los valores que definan las relaciones entre familias y profesorado, entre profesorado y alumnado y entre profesorado y comunidad educativa donde el reconocimiento de la diversidad humana está garantizado como elemento de valor y no como lacra social.

Una vez expuestas mis consideraciones sobre las barreras didácticas que impiden la construcción de una escuela para todas y para todos, y asimismo, cómo salvar aquellas barreras, e vuelvo a preguntar: ¿es posible construir una escuela sin exclusiones?

Y mi respuesta es un si rotundo, pero lo podremos lograr si sencillamente respetamos a los niños en su diferencia como derecho humano y como valor. Las niñas y los niños que acuden a la escuela no son niñas ni niños 
imperfectos, sólo son eso: niñas y niños. No son seres inmaduros e incompletos, porque no les fal ta nada delo peculiar deser niña o niño; son, sencillamenteniños. Y en eseser niños sepuedeser negra, pobre, esloveno o colombiano, tener síndrome de Down, padecer una enfermedad contagiosa, ser paralítico cerebral o ser sencillamente niña o niño, y nada de esto configura un defecto ni una lacra social, sino un valor. La natural eza es diversa y no hay cosa más genuina en el ser humano que la diversidad. La cualidad más humana de la naturaleza es la diversidad. Y lo mismo queno hay dos amapolas iguales, no existen dos personas iguales. No existe Historia de la Humanidad si no existen niñas y niños. No existe Historia de la Humanidad si no hay historia de la diversidad. La Historia de la Diversidad es la Historia de las niñas y de los niños.

Con estas palabras no pretendo que cambieel ser humano, sino quese produzca un cambio cultural. Y ese cambio cultural sólo es posiblea través dela educación y la cultura. Personalmentepienso quehoy más quenunca cobra vigencia la convicción de que es la educación la única energía posible para sacar al mundo de la enfermedad en la que vivimos. Sólo así podríamos 'construir el sueño' de una sociedad más justa, más democrática, más tolerante y más respetuosa.

En fin para poder construir esa escuela sin exclusión es necesario culturas inclusivas, políticas inclusivas y prácticas pedagógicas inclusivas. Con las prácticas pedagógicas simples no se puede lograr una escuela sin exclusiones, se hace necesaria una pedagogía más compleja donde las personas y las culturas diferentes puedan 'aprender a aprender'. N osotros lo venimos haciendo en el Proyecto Roma a través de lo que denominamos proyectos de investigación, que son un modo de aprender en colaboración en el aula (LÓPEZ MELERO, 2004). También hay otras prácticas pedagógi cas ejemplares en estesentido tales como El Programa de Desarrollo Escolar (School D evelopment Program) del profesor James Comer de la Universidad de Yale (COMER, 1998) o el programa de las Escuelas A celeradas (A ccelerated schools), surgidas también en EEUU en 1986 por el profesor Henry Levin de la Universidad de Stanford (1994). No podemos olvidar tampoco el conjunto de proyectos denominados Educación para Todos (Education For All) impulsado por el profesor Robert Slavin y colaboradores $(1996,2001)$ desde el Centro de investigación para la educación del alumnado en riesgo en la Universidad Johns Hopkins de EEUU, y los trabajos de a Stainback e Stainback (2001). Todos estos son ejemplos de quela escuela sin exclusiones es posible, tan sólo es cuestión de tener una actitud para iniciar procesos de cambio y transformación. Ejemplos hay, ahora corresponde que estemos dispuestos a ponerlos en práctica.

Por todo ello y siendo un poco atrevido voy, al final de este escrito, a apuntar algunas ideas desde la consideración de la cultura de la diversidad como alternativa y revolución cultural para el siglo XXI. 


\section{Al final mi compromiso personal y profesional}

Estas palabras nos pueden llevar a pensar que la utopía existe. Efectivamentela utopía existey para mí es una democracia sin fronteras. Soy utópico porque la educación es utopía, y la utopía yo la considero como ese deseo por un mundo mejor. En ese sentido deseo ser utópico ¿A caso es posible una educación en valores desvinculada de una dimensión utópica? Educación, ética y política son los tres vértices de esa figura de sociedad democrática participativa que es necesario construir en la perspectiva de un nuevo humanismo donde los valores fundamentales sean la libertad y la igual dad.

La utopía no puede morir. Si así fuese tendríamos queadmitir con Roa Bastos (1996, p.37) "que si la utopía muere, la raza humana está maldita para siempre". El concepto de utopía va unido a la idea de la construcción de un mundo mejor, de una sociedad mejor y delos cambi os y transformaciones necesarios para conseguirlo. Siempre expresa un ideal de cambio hacia algo nuevo y mejor. Si se secan los manantiales utópicos, la vida de los seres humanos se transforma en un desierto donde sólo florecerían el conformismo, la apatía, la trivialidad y el oportunismo: la deshumanización humana. Hoy más quenunca hay que recordar las palabras de Oscar Wilde $(2004$, p.5) “El mapa que no contenga el país de la utopía no merece una mirada"

Esta visión del concepto de utopía unido a los términos de respeto, justicia y dignidad humana, rompe con el concepto peyorativo de la utopía como algo irrealizable, y se inserta en el vivir y en el convivir humano como al go que "no es, pero que podría ser", pragmautópico, dice Eisler (1994). Así es como el poeta hace visible, con su mirada poética, lo que ha quedado oculto por la historia, ya que revela aspectos y dimensiones delo humano quehabiendo sido fundamentos del vivir humano, han quedado sumidos o escondidos bajo otras en la transformación cultural dela humanidad, pero que no han desaparecido y con sus emociones y sentimientos nos hacen sentir qué mundo queremos vivir. Más aún, nos devuelve la ilusión y la responsabilidad de elegir qué mundo queremos vivir, como un mundo de respeto, cooperación, justicia, tolerancia, conformela emoción fundamental del amor. Sin embargo, la globalización económica está unida a la ciencia-ficción al mostrarnos un mundo deenajenación cultural, abusos, jerarquías, agresión, discriminación y obediencia. Atravesamos un mal momento en la sociedad actual con el pensamiento único y la globalización, conceptos polisémicos y complejo que hace referencia a la manera diferente de entender y desarrollar las relaciones sociales, económicas, políticas y culturales, pero también estamos viviendo en la injusticia más globalizada como apuntaJ osé Saramago (2002), donde la competitividad, el individualismo, la intolerancia, la injusticia, etc., son los (contra)valores que imperan y caen como una losa contra aquellos que luchan contra la gl obalizada injusticia. Como dice Henry Giroux (2001, p. 129): “la utopía delos proyectos democráticos en desarrollo radica tanto en criticar el orden existente de las cosas como en utilizar el ámbito cultural y educativo para intervenir de 
manera directa en el mundo y para luchar por el cambio dela actual configuración del poder de la sociedad".

Este modelo educativo nuevo que convertiría al ciudadano en una persona crítica de resistencia (SARAMAGO,. 2002), gira en torno a la idea central decreernos capaces de generar nuevas cuestiones que canalicen la energía necesaria para disponer de un nuevo enfoque moral que contrarreste a las instituciones y a las fuerzas que están haciendo denuestras vidas y de la sociedad en la que vivimos un verdadero infierno. Por eso somos libres si tenemos las ideas claras para generar una opción. Y yo he formulado una opción política y educativa. Opción política y educativa es tomar una postura frentea la real idad social; es no quedar indiferente antela justicia atropellada; es no permanecer indiferenteantela libertad conculcada o antelos derechos humanos violados; es luchar contra la injusticia dela trabajadora o el trabajador explotado; es denunciar permanentementela fal ta de respeto hacia la mujer, la intolerancia política, religiosa, étnica o de discapacidad. En fin, tomar partido por la justicia, por la libertad, por la democracia, por la ética y por el bien común es opción política y es hacer política. Opción política y educativa es luchar por la cultura de la diversidad frente a la cultura de la discapacidad y ésta es mi ideología y mi vida, como un sistema de creencias y valores que trazan el camino para la acción. En fin, la cultura de la diversidad es mi compromiso ideológico y educativo.

Mi compromiso político y educativo nace precisamente de esta aspiración mía y de este deseo de colaboración en la construcción de un nuevo model o educativo que rompa con el principio neoliberal por excelencia del homo sapiens y nos traslade al homo amans, como verdadero objetivo de una escuela democrática quesecomprometeen defender los derechos humanos y la legitimidad de cada cual en su diferencia. Y, como Gandhi advirtió, es una mentira pretender ser no violento y permanecer pasivo antelas injusticias sociales. La responsabilidad política y educativa no radica en afirmar que 'yo ya cumplo con mis deberes' sino en hacer que los cumplan quienes no los cumplen. En esta lucha del ethos democrático debemos permanecer o quizás tengamos que dar un paso más, como nos recuerda Touraine (1997, p.7): "Ya no queremos una democracia de participación; no podemos contentarnos con una democracia de deliberación; necesitamos una democracia de liberación". Que es tanto como decir, recordando a Freire (1990), que es necesaria una educación como práctica de la libertad.

En fin, más allá del valor simbólico eincluso más allá de la denuncia y repulsa a la escuela segregadora y homogeneizanteque se pueda encontrar en este escrito, he de anunciar mi compromiso profesional y personal en la construcción de una escuela sin exclusiones unida por los valores humanos de cooperación y solidaridad que frene el despliegue feroz del individualismo y la competitividad que se generan en la escuela neoliberal.

A caso el verdadero descubrimiento en el ser humano no consista en buscar nuevos paisajes sino en poseer nuevos ojos (PROUST, 1997). Eso es lo que 
yo hehecho durantetoda mi vida, mirar deotra manera a las personas consideradas socialmente como 'deficientes' y convivir con las culturas minoritarias. ¿De qué manera? De aquella que me ha hecho a mí crecer como persona.

Quiero terminar este escrito recordando unas palabras de Eduardo Galeano, quien contaba que estaba con un amigo suyo, Fernando Birri, un tipo encantador, cineasta latinoamericano, de esos que Paulo Freire quería, o sea locamente sano y sanamente loco, que está más loco que sano pero... bueno, nadie es perfecto. Decía que estaban juntos Eduardo y Fernando con unos estudiantes en Cartagena de Indias, en Colombia, cuando uno de ellos le preguntó a Fernando para qué sirve la utopía. Birri le respondió: “¿Para qué sirve la utopía? Es una pregunta queyo mehago todos los días, yo también me pregunto para quésirvela utopía. Porque la utopía está en el horizonte y entonces si yo ando diez pasos la utopía se aleja diez pasos, y si yo ando veinte pasos la utopía se coloca veinte pasos más allá; por mucho que yo camine nunca, nunca la al canzaré. Entonces ¿para quésirve la utopía?, para eso, para caminar.

Así, queridos colegas y amigos, no dejemos de caminar.

\section{Referências}

COMER, J. Comer school development program. Yale: YaleUniversity, 1998

EISLER, R. EI cáliz y la espada: la al ternativa femenina. Madrid: Cuatro Vientos Martinez de Margúa, 1994.

FREIRE, P. La naturaleza política dela educación: cultura, poder y liberación. Madrid: Paidós/ MEC, 1990.

GARDER, Howard. Inteligencias múltiples: la teoría en la práctica. Barcelona: Paidós, 1995.

GIROUX, H. Cultura, política y práctica educativa. Barcelona: Grao, 2001.

HABERMAS, J. La inclusión del otro. Barcelona: Paidós, 1999.

KHUN, L. La estructura de las revoluciones científicas. Madrid: Fondo de Cultura Económica. 1977.

LEVIN, H. A ccelerated schools alter eight years. Palo A Ito: Stanford University, Accelerated schools project. 1994.

LEWONTIN, S. et al. N o está en los genes. Barcelona: Grijal bo Crítica, 1990.

LÓPEZ MELERO, M. EI proyecto Roma: una experiencia de educación en valores. Málaga: Aljibe, 2003.

. Construyendo una escuela sin exclusiones: una forma detrabajar en el aula con proyectos deinvestigación. Málaga: Aljibe, 2004.

LURIA, A.R. El cerebro en acción. Barcelona: Fontanella, 1974.

ROA BASTOS, A. M etaforismos. Barcelona: Ed. Edhasa, 1996.

PROUST, M... En busca del tiempo perdido. Madrid: Alianza, 1997. 
MELERO, M. L.

SARAM A GO, J. El hombre duplicado. Madrid: A lfaguara, 2002.

SLA VIN, R. Education for all. Lisse: Swets y Zeitlinger, 1996.

STAINBACK, S.; STAINBACK, W. A ulas inclusivas: un nuevo modo deenfocar el curriculo. Madrid: Ed. Nancea, 2001.

TOURAINE, A. ¿ ¿Podremos vivir juntos? I guales y diferentes. Madrid: PPC, 1997.

UNESCO. D eclaración sobrela raza y los prejuicios sociales. París: Organización delas Naciones Unidas para la Educación, la Ciencia y la Cultura, 1981.

UNESCO. D eclaración mundial sobre educación para todos. Jomtien, 1990

UNESCO. D eclaración de Salamanca y marco para la acción. Salamanca, España, 1994

VYGOTSKY, L. S. Pensamiento y lenguaje. Buenos Aires: La Pléyade, 1978.

WILDE, O. Un marido ideal. Madrid: Ed. Losada, 2004. 